settings head the list of priorities for registration by the council.

Education and training are currently among the most important issues in the personal social services. Community care requires social workers to extend their range by adding budgetary, managerial, and coordinating responsibilities to their traditional tasks of assessment and casework. Training must also cover the knowledge and skills required for working with both children and adults and provide the ethical and legal grounding that social work needs. Two years of full time education is too short a time to establish competence across the whole range of a social worker's statutory duties; the issue is not whether a third year is desirable but whether it should be spent before or after qualification.

Social workers often operate in circumstances where moral values are confused and in conflict and where no single outcome is likely to satisfy all those concerned. Compulsory admission, child care, child protection, fostering and adoption, assessing risk in community and residential careall these are matters on which social workers encounter divided views on values, principles, and policy. Social work must therefore have a secure ethical basis for its professional and educational structures.

Practitioners confronted by moral dilemmas and insoluble problems also need the guidance and support of a comprehensive professional organisation. Its advice and findings then form part of the bedrock of professional education. The absence of such a professional structure hampers the incorporation of ethical and technical elements into education. The proposed general council would fill this gap effectively and economically.
Social work's close association with local government has brought it both costs and benefits. Social workers, in a role that requires professional self-direction, are asked to function as part of the welfare bureaucracy and as front line troops performing statutory duties. But local government also provides social workers with a crucial role in protecting vulnerable people and in securing valuable services for them. It will remain a rewarding setting for the practice of social work, and social workers will continue to make an important contribution to the welfare of the community from a base in local government. The necessary condition is that they receive responsible political leadership, effective management, and proper resources.

The narrow focus of statutory services now prevents social work from directly addressing the consequences of unemployment, poverty, and homelessness. A new statutory framework is required for services to adults that redirects the energies of social work to these needs and fulfils all the aspirations of community care policies. Social work should also seek to develop as a professional activity in voluntary and private agencies and in the NHS. The requirement for local authorities to meet the health service's need for social work has broken down in significant areas. Health services should once again be able to employ social workers, and social work should be one of the services offered by NHS hospitals and trusts, community health services, and general practices.

BILL UTTING Chairman

National Institute of Social Work,

5-7 Tavistock Place,

London WC1H 9SS

\title{
Short acting benzodiazepines
}

\section{Dream drugs or nightmare?}

Benzodiazepines with a short half life have recently become the subject of considerable controversy, which culminated in the suspension of one such drug, triazolam, by regulatory authorities in several countries including Britain. In addition to rebound phenomena occurring when treatment is stopped, it has been claimed that the rapid elimination of these drugs may result in withdrawal symptoms during treatmentincluding amnesia, delirium, psychosis, behavioural disturbance, and affective disorders. The manufacturers of triazolam, however, have consistently maintained "full confidence in the efficacy" of their product, ${ }^{1}$ and recently Jonas claimed that the conclusions of triazolam's most vociferous critics result from "poor methodology, inadequate test measures, and improper interpretation" of data. ${ }^{2}$

Here we address two questions fundamental to the debate. Do the alleged side effects occur, and, if so, are they more commonly observed with triazolam than with other benzodiazepines? A review of spontaneous reports to the United States Food and Drug Administration showed that side effects were reported up to 100 times more commonly for triazolam than for temazepam per prescription, ${ }^{3}$ and the Committee on Safety of Medicines has also received an apparent excess of reports of memory and affective disturbance associated with triazolam. ${ }^{4}$ Obviously case reports and drug monitoring data are open to many sources of bias, and a drug that has been the subject of media attention may attract closer scrutiny of its apparent adverse effects by both doctors and their patients. The number of reports is not, however, easily ignored, particularly when combined with the results of controlled studies.

The least controversial symptom is rebound insomnia. A virtually complete consensus exists that this often occurs when any benzodiazepines, including triazolam, are stopped. ${ }^{5}$ Indeed, rebound insomnia can even occur after a single dose of triazolam. ${ }^{6}$ Kales and colleagues found that the sleep of insomniac patients was poorer relative to baseline after they stopped both triazolam and temazepam (short and intermediate acting benzodiazepines respectively) but that the size of the effect was greater with triazolam. ${ }^{6}$ Although Jonas ${ }^{2}$ points to multiple publication of data from the same group's earlier study ${ }^{7}$ - which may have given a false impression of the weight of the evidence-the new study confirms this group's results. ${ }^{6}$ More importantly, it is consistent with independent work by other groups. These have shown that though it is certainly not unique to triazolam, rebound insomnia is most common and severe for compounds with short half lives. ${ }^{58}$

Probably all benzodiazepines have memory impairing side effects, ${ }^{9}$ and, again, clear evidence exists that triazolam has amnesic side effects at therapeutic doses..$^{10}$ In a comparison of data from two placebo controlled studies of the amnesic effects of triazolam and temazepam, Scharf and colleagues found that triazolam but not temazepam was associated with impaired delayed recall. ${ }^{11}$ Similarly, in a parallel double blind study of flurazepam, temazepam, triazolam, and placebo, 
patients taking triazolam had more impairment of memory than the others. ${ }^{10}$

Bixler and colleagues have described a different, more worrying form of amnesic effect: the period of impaired recall included events occurring the day after ingestion of the drug (rather than just before or during the sleep period). ${ }^{12}$ Five of six patients in the group treated with triazolam reported subjective memory impairment, yet one of these same patients reported a single episode during the placebo phase. Also, the group treated with triazolam, but not the group treated with temazepam, displayed an objectively impaired ability to recall tasks performed the morning after they took the drug.

The greatest controversy concerns the association of triazolam with psychiatric disturbances during the course of treatment, which was first suggested by anecdotal reports. Subsequently in a double blind study Morgan and Oswald reported that treatment for three weeks with triazolam but not loprazolam, a longer acting benzodiazepine, was associated with an increase in daytime "anxiety" in poor sleepers. ${ }^{13}$ This finding was replicated in a larger study in which triazolam, but not lormetazepam, increased anxiety compared with placebo. ${ }^{14}$

We agree with Jonas that these studies probably did not measure "pure" anxiety and that the clinical severity of the drug's effect is obscured both by the rating method and by the form of analysis. ${ }^{2}$ It is clear, however, from the clinical descriptions that many of the reactions with triazolam were of at least moderate severity and included anxiety, depression, and, in a few cases, psychosis. Kales and colleagues have observed similar results. ${ }^{7}$ In their studies the "anxiogenic" effect was limited to midazolam and triazolam, both with very short half lives.

Although Jonas argues that Oswald's data are flawed by multiple systematic biases and that the data of Kale's group are equally unreliable, independent support for an association between psychiatric disturbance and treatment with triazolam has come from two other sources. One controlled study found an increase in restlessness and anxiety during three weeks of treatment with low dose triazolam; ${ }^{15}$ another small placebo controlled study found more depressive symptoms with triazolam. ${ }^{16}$

Overall, then, most sources agree that rebound insomnia, amnesia, and psychiatric disturbance, although not unique to triazolam, are more often associated with its use than with other benzodiazepines. As always, in considering usefulness it is necessary to balance the benefits peculiar to a drug with its risks. In our opinion, there are numerous alternative treatments for insomnia available including benzodiazepines, non-benzodiazepines, and non-pharmacological methods; triazolam has no compelling singular benefits that outbalance its risks.

MICHAEL C O'DONOVAN MRC travelling fellow

Center for Cancer Research,

Massachusetts Institute of Technology,

77 Massachusetts Avenue, E17-536,

Cambridge, MA 02139, USA

PETER McGUFFIN

University of Wales College of Medicine, Professor of psychological medicine

Cardiff CF2 4XN

1 Kryzwicki KT. Safety of triazolam. Lancet 1991;338:632.

2 Jonas JM. Idiosyncratic side effects of short half-life benzodiazepine hypnotics: fact or fancy? Hum Psychopharmacol 1992; 7:205-16.

3 Wysowski DK, Barash D. Adverse behavioural reactions attributed to triazolam in the Food and Drug Administration's spontaneous reporting system. Arch Intern Med 1991;151:2003-8. 4 The sudden withdrawal of triazolam - reasons and consequences. Drug Ther Bull 1991;29:89-90.

5 Lader M, Lawson C. Sleep studies and rebound insomnia: methodological problems, laboratory findings and clinical implications. Clin Neuropharmacol 1987;10:291-312.

6 Kales A, Manfredi RL, Vgontzas AN, Bixler EO, Vela-Bueno A, Fee EC. Rebound insomnia after only brief and intermittent use of rapidly eliminated benzodiazepines. Clinical Trials and Therapeutics 1991;49:468-76.

Kales A, Soldatos CR, Bixler EO, Kales JD. Early morning insomnia with rapidly eliminated benzodiazepines. Science 1983;220:95-7.

8 Gillin JC, Spinweber GL, Johnson LC. Rebound insomnia: a critical review. $f$ Clin Psychopharmacol 1989;9:161-72.

9 Curren HV. Benzodiazepines, memory and mood: a review. Psychopharmacology 1991;105:1-8.

10 Greenblatt DJ, Harmatz JS, Englehardt N, Shader RI. Pharmacokinetic determinants of dynamic differences among three benzodiazepine hypnotics. Arch Gen Psychiatry 1989;46:326-32.

11 Scharf MB, Fletcher K, Graham JP. Comparative amnesic effects of benzodiazepine hypnotic agents. F Clin Psychiatry 1988;49:134-7.

12 Bixler EO, Kales A, Manfredi RL, Vgontzas AN, Tyso KL, Kales JD. Next day memory impairment with triazolam use. Lancet 1991;337:827-31.

13 Morgan K, Oswald I. Anxiety caused by a short-life hypnotic. BMF 1982;284:942.

14 Adam K, Oxwald I. Can a rapidly-eliminated hypnotic cause daytime anxiety? Pharmacopsychiatry 1989;2:115-9.

\title{
1966 revisited: bright new contract or brave old world?
}

\author{
General practice's attempt to regain the initiative
}

After several years of mauling by the government the General Medical Services Committee has picked itself up and returned to the ring. The discussion paper on the future of general practice produced by its chairman, Ian Bogle, and now endorsed by the committee, is a succinct and lucid attempt to regain the political initiative for the profession. ${ }^{12}$

It contains three basic arguments. Firstly, general practitioners can avoid the imposition of quality control only by conceding that bad practice exists and by promoting peer controlled reaccreditation and audit. Secondly, increasing managerial control of general practice is here to stay. Finally, the profession should accept the purchaser-provider split and negotiate a more favourable contract that emphasises quality of care.

Acceptance of quality of care as a central concern would represent the final defeat of the traditional defenders of general practice, coming as it does some 15 years after the Royal College of General Practitioners dared to speak of unacceptably low standards of practice, ${ }^{3}$ and nearly a decade after the triumphalism of General Practice: a British Success. ${ }^{4}$ Nevertheless, bad practice is hard to face and it is easier to find scapegoats-the few who are careless, incompetent, and even dangerous-than to accept that we are all "bad" at times. Variable quality care derives in part from professional isolation, from the rapid development of medical science itself, and from the fatigue of being on a treadmill.

General practitioners operate as franchisees, getting support from the franchiser, the NHS, but without losing autonomy and some element of personal risk. ${ }^{5}$ The 1966 family doctors charter increased the support and reduced the risk without compromising autonomy, and so proved both popular and successful. The 1990 contract reduced support, increased risk, and tightened control as the NHS management sought both to extend and to standardise the services provided by its franchisees. It is hardly surprising that it has been unpopular and stressful for general practitioners, ${ }^{6}$ but the logic of franchising makes further tightening of management control likely. ${ }^{7}$ 